\title{
TEACHING ENGLISH AT THE SECONDARY LEVEL: A STUDY OF TEACHERS' PERCEIVED DIFFICULTIES IN IMPLEMENTING CLT IN BANGLADESH
}

\author{
MD. ASHIKULLAH ${ }^{1} \&$ MD. SHAKHAWAT HOSSAIN ${ }^{2}$ \\ ${ }^{1}$ Lecturer, Department of English, Bangladesh Army University of Science \& Technology, Saidpur, Bangladesh \\ ${ }^{2}$ Senior Lecturer, Department of English, Northern University Bangladesh, Dhaka, Bangladesh
}

\begin{abstract}
For the last thirty years, the field of TESOL (Teaching English to Speakers of Other Languages) has been influenced in its development by different issues which have led to increasing demands for an inquiry into the social, economical and political aspects of English language teaching. In the light of such demands, this empirical survey looks into English teachers' perceived difficulties in implementing Communicative Language Teaching (CLT) approach, the impact of these difficulties on language teaching, on the learners from the Bangladeshi ELT context. Qualitative results show that teachers perceive these difficulties in different ways, but there are noticeable patterns which suggest that these difficulties, to a great extent, make CLT ineffective for teaching English at the secondary level in Bangladesh.
\end{abstract}

KEYWORDS: Communicative language teaching (CLT), TESOL \& Teachers' perceived difficulties

Received: Dec 18, 2017; Accepted: Jan 09, 2018; Published: Feb 03, 2018; Paper Id.: IJELFEB201812

\section{INTRODUCTION}

The study presents analysis of English language teachers' perceptions regarding the difficulties they face in practicing CLT principles in the Bangladeshi context. With the innovation of Communicative Language Teaching (CLT) in the early 1970s, classroom activities have been changed tremendously in recent years. To make students communicatively competent and with a view to engaging them in real life like situation, different types of interesting classroom activities have been developed. Authentic language use and classroom exchanges where students engage in real communication with one another have become quite popular. Karavas \& Doukas (1996) have found that although most teachers profess to be following communicative approach, in practice they are following more traditional approaches. Broadly speaking, the commutative approach appears to have brought more innovation on the level of theory than on the level of teachers' actual classroom practices.

The present investigation aims at showing how Bangladeshi English language teachers, working at the secondary level institutions, perceive the challenges and difficulties in implementing CLT principles in teaching English in contrary to the increasing demand for CLT for teaching English all over the world. In Bagladesh, the Communicative Language Teaching (CLT) approach was first introduced in 1996. After that students are being taught communicatively using the communicative language teaching methodology. It was thought that CLT would develop learners' communicative competence and thereby strengthen the human resource development of the Government of Bangladesh (NCTB, 2003 cited in Hamid \& Baldouf, 2003). The communicative approach has also faced correlative interventions despite years of schooling. "Our students are very weak in English and as a result, they cannot apply English in their practical lives successfully" (NCTB, 2003, cited in Hamid \& Baldouf, 
2003). It is twelve years since CLT was first introduced in the National Curriculum of Bangladesh, but still often CLT is criticized by educators and linguists because of its inappropriateness and inefficiency. So the question comes if it is really possible to apply CLT for the improvement of English language teaching in Bangladesh.

\section{LITERATURE REVIEW}

For more than three decades, much emphasis has been put on teaching English language using a communicative approach. Communicative approach emerged as a reaction against the rigid grammar-translation method and audio lingualism with a view to developing learners' communicative competence in a foreign or second language. Communicative competence is a term coined by Dell Hymes (1972), to refer to our ability to use social and functional aspects of a language for meaningful communication. Here the main emphasis is not only on the production of grammatically correct sentences but also on the knowledge of where, when, and how to use these sentences in a communicative event (Richards \& Rogers, 2003). The notion of communicative competence is further enveloped by Canale \& Swain (1980). They have divided the communicative competence into four basic components; grammatical competence, sociolinguistic competence, discourse competence and strategic competence. In addition to these views, Wilkins (1972) defines communicative competence as the ability to understand and express own ideas. Instead of gaining mastery on linguistic items, CLT approach is more concerned with the active participation of learners, their interest and belief and the necessity of linguistics discussion and vocabulary (Richards \& Rogers, 2003).

In Communicative Language Teaching (CLT) approach, language teaching makes use of real life situations; the situation that we face in our daily life. Learners are the active participants in all kinds of classroom activities. In this way learners get the chance to have a great exposure in the target language. Teachers in the CLT classrooms act as facilitators or monitors of the learners' progression in the target language learning (Freemen, 1986). However, researchers have argued that taking a method originated in one part of the world and using it in another part causes difficulties and challenges (Holliday, 1994; Kramsch \& Sullivan, 1996; Pennycook, 1989). These researchers have opined that education is essentially culture based and for a good teaching practice socio-cultural background of a country must be taken into account. Chowdhury (2010) has pointed out that due to the introduction of CLT in Bangladesh, nowadays English is not considered as a foreign language. Ramanthan (1999) has said that the much professed and popular theories devised in the inner circles of countries may or may not be compatible with the teaching conditions in the outer circle countries.

Ellis (1994) has examined the applicability of CLT in Vietnamese context and found that one of the major obstacles in using CLT in Vietnam was teachers' excessive dependence on the traditional teaching practices. The teachers have reported that they lack sufficient knowledge of target language culture. Ellis has ended his study saying that the ideal form of ELT is not effective for Vietnamese context because it is not matched by adequate teacher training, communicative language materials and suitable learning environment. In another study conducted by Vassilopoulos (2008) in South Korea, it is found that before adopting CLT, South Korea needs to change their fundamental approaches to education because the student-centered, fluency-focused and problem-solving tasks may come into conflict with the predominant teachercentered and accuracy-focused classrooms. In China too, where the need for adopting CLT has come from the unsatisfactory teaching results of the grammar-translation method, the introduction of CLT has faced many obstacles (Liao, 2000). Concerning the use of CLT in Chinese context, Liao states that the teachers believe that it is not feasible to adopt CLT because China has its special characteristics,teachers' inability to teach communicatively and grammar-focused examination pressure. Islam \& Bari (2012), on the implementation of CLT in Bangladesh, have revealed that teachers fail 
to motivate students to develop communicative competence as most of the students concentrate on syllabus and passing or getting good marks in examinations.

\section{RESEARCH METHODOLOGY}

The data for the present study was collected by means of a questionnaire survey, classroom observations and focus group interviews among practicing English language teachers at ten different high schools located in different areas of Bangladesh. The survey was carried out on twenty randomly selected English language teachers. The researchers themselves went to the schools and collected information directly from the twenty teacher respondants. They have also taken focus group interviews of five teachers. All the participant teachers have at least an MA in English (MAE) or MA in ELT degree. Some of them have also attended seminars and training sessions on the CLT approach of English language teaching. The range of their teaching experience is $2-7$ years.

\section{FINDINGS \& ANALYSIS}

The data was analyzed using the content analysis, which is a widely used qualitative research technique. The researchers had thoroughly read the participants' replies to any particular question and then summarized the views. The summaries of the participants' responses were divided into as many categories as possible. To maintain the validity and reliability of the responses, the researchers collected the same data from many dimensions. The major findings for each of the questions have been stated below:

Reasons for Using CLT Principles in Classroom Teaching: Among the twenty teachers, seventeen teachers have replied that they use ELT principles in their classrooms and three teacher have said that they have not tried it yet because of the large class sizes. Fifteen teachers have been found using it in the classroom because the books are designed following the CLT methodology. All the twenty teachers have showed their interests in using the CLT method in the classrooms because they have found it innovative and creative.

Students' Low Motivation to Develop Communicative Competence: Though the teachers are interested in implementing CLT in language classrooms, they face many problems because students are less motivated to take part in classroom activities. All the teachers have strongly agreed on the ground that students lack motivation to develop their communicative competence. They have found that students are more interested in memorizing the things that will come in the examinations. They have claimed that when they want to practise such activities as role play or information-gap, the students are not willing to take part in the activities as they know that these tasks hardly help they to prepare for the examninations.

Faulty Testing System: In a focus group interview, all the five teachers have showed a strong dissatisfaction about the examination system. They criticized it because the examinations are not conducted for the testing of all language skills. In our examination system, there are only two skills; writing and reading to be tested, and other two skills; speaking and listening have been ignored. The teachers have further stated that students like to participate in those activities that they find important for the examinations. As listening and speaking, two major skills to communicate, have not been included in our testing system, the students feel less motivated to develop them. Moveover, the teachers have found that the testing of reading and writing is faraway from appropriateness. Students are given such reading tasks that they have read earlier. The teachers have claimed that with such "seen passages" they will never be able to judge the actual reading ability of the students. Regarding the writing test, the teachers have identified that each year some common paragraphs or 
essays are set in the question papers repeatedly and students, therefore, memorize them for passing the examinations devoid of doing something creative in the classroom.

Students' Low Proficiency in the Target Language: Another difficulty pointed out by the teachers is students' low proficiency in English. All the teachers have strongly agreed or agreed to this point. They have pointed out that students enter the secondary level of education without having the proper command of English required for engaging in CLT activities. They have said that there is a lack of qualified English teachers at primary schools. And for this reason, the students lack in background knowledge. Therefore, all the teachers have urged for ensuring a strong primary education before entering the high schools.

Limitation of Time and Number of Classes: The teachers have claimed that they do not get enough time for the development of effective materials as they have to rush for completing the syllabus on time. They further added that the time allotted for each class ( 45 minutes) is not sufficient enough for having communicative activities.

Few Opportunities for CLT Training: Most of the teachers have strongly agreed on the point that they have less opportunity for CLT training. There is less awareness regarding the principles of CLT among teachers. In addition, a number of teachers have confessed that they do not have a clear idea about the principles and techniques of Communicatve Language Teaching (CLT).

Large Class Size: In a focus group discusssion, the teachers have said that when they assign students with a group work, only a few students take part in it and most of them remain silent. While asked if they monitor the students activities or not, the teacher have stated that the classes are too large to monitor. In case of role play, they have found that it is very difficult to engage all the students because the number of students at a particular class sometimes exceeds 100.

Culturally Inappropriate Lessons: The teachers have mentioned that not all the lessons included in the English textbooks are culturally appropriate for the Bangladeshi learners. They have agreed on the point that teachers as well as the students do not have the sufficient knowledge of the target language culture. As there is a profusion of materials that reflect the Western culture, both teachers and students fail to understand the meanings of some utterances or words in specific contexts which results in a less communicative classroom.

\section{DISCUSSIONS}

The teachers have claimed that the students lack proper motivation to improve their communicative competence. They are not usually keen on improving their communication skill in listening, speaking, reading and writing. Conversely, they are more concerned with what is important for the examnination purpose, i.e. how they can obtain good grades. This finding matches with the research work carried out by Islam and Bari (2012) where they have found that most Bangladeshi students learn a second language during the primary and secondary levels of education largely for passing the examinations. Once they manage to pass an English examination, they show utter reluctance to language learning and even they are so much worried of taking an English language examination.

The teacher have also expressed their complete dissatisfaction with the testing system in Bangladeshi schools and colleges. They have argued that the testing system does not include listening and speaking tests and hence the students lack interest/motivation to engage them in such real life conversations that will help them to be prepared to fulfill their communicative needs. This view of the teachers is comparable to Barman, Sultana \& Basu (2012) who have identified testing system as one of the major constraints in implementing CLT in Bangladesh. As regards the testing system, the 
teacher have pointed out that the typical testing system does not measure the actual language ability of the students. This view of the teachers matches well with a study carried by Hamid \& Baldouf (2003) on the effectiveness of CLT in Bangladesh which reveals a mismatch between the SSC test scores and the actual talent of the students.

With regard to the large class size, the teachers are divided in their opinions. Four of the teachers do not consider large classes as an impediment to the application of CLT in Bangladesh. But the other sixteen teachers have found the large class size as a big problem. Probably the four teachers have never experienced teaching in a large class and hence it does not seem as a problem to them. In addition, in a study, Barman, Sultana \& Basu (2012) have found that large class size is one of the fundamental problems in implementing CLT in Bangladesh.

In addition, the respondents have mentioned that they are not provided with sufficient training facilities on CLT. As the teachers are not well trained on the CLT method of language teaching, they fail to use effective communicative activities at their classes. As a result they become doubtful of what to do and how to carry on the classroom activities. Being ignorance of effective communicative activities, the teachers usually depend on online materials or resources available on the Internet. As these online materials represent the western cultures, students as well as the teachers on some occasions fail to understand the contexts of the materials and therefore the lessons become dry and boring. In Bangladesh, the classroom teachers are usually authoritarian in nature. As there is a no friendly realatioships between the teachers and their students, the students are fearful of their teachers and this general Bangladeshi custom prevents students from getting involved in genuine communications at the classes. In addition, due to the absence of culturally congruent materials or communicative activities, students fail to take part in the classroom activities enthusiastically and even cannot make healthy interactions in the classroom situations.

\section{PEDAGOGICAL IMPLICATIONS}

From the findings, we may have, to some extent, a vivid picture of the problems in implementing CLT in Bangladesh. Though this type of small study cannot claim to make concrete recommendations for the proper application of CLT in our country, a few suggestions may be made:

- The English language testing system can be changed. Students should not be asked to answer items that they have memorized earlier and there is an utmost necessity to include reliable speaking and listening tests in examinations.

- Teachers can motivate students to participate in diverse CLT activities by making classroom activities interesting.

- To build up a strong base in English, there is a need for qualified teachers at the primary level who will make them speak, listen, write and read in English from their early years of study.

- The secondary schools can offer English foundation courses to elevate students' proficiency levels and then they will be able to cope with the CLT activities.

- Large classes can be broken into two or more small classes. And for this purpose, the number of English teachers needs to be increased.

- There is also a need for arranging teachers' training sessions on CLT. These training sessions can be arranged several times a year to let the teachers know the advance knowledge of CLT approaches. 


\section{CONCLUSIONS}

This paper has aimed at finding out the difficulties faced by the English language teachers in implementing CLT in the secondary level education of Bangladesh. It has also tried to offer some potential solutions to the ongoing problems faced by the teachers and students in English language teaching and learning using the CLT method. The major problems identified are - students' low motivation to develop communicative competence, faulty testing system, students' low proficiency in the target language, limitation of time and number of classes, few training opportunities on CLT for teachers, large class size, culturally inappropriate lessons etc. CLT activities are comparatively more complicated to plan and apply than the other approaches and methods. However, this study has not been carried out to build up any theory rather it provides some qualitative results and some emerging patterns on how Bangladeshi English language teachers perceive the problems in their teaching of English and their insights into how to overcome them. Finally, it is expected that the qualitative results and insights gained from the survey, to some extent, will make the ELT practitioners aware of the present status of CLT as a language teaching methodology in Bangladesh.

\section{REFERENCES}

1. Barman, B., Sultana, Z. and Basu, B. L. (2006). ELT: Theory and Practice. Bangladesh: Daffodil International University.

2. Chowdhry, M. R. (2010). "International TESOL training and EFL contexts", available from http:// alwaysingreen.blogspot.com/2010/12/International-tesol-training-and-efl.html accessed on 08 December 2018.

3. Canale, M., \& Swain, M. (1980). Theoretical bases of communicative approaches to second language teaching and testing. Applied Linguistics, 1(1):34-47.

4. Ellis, G. (1994). The appropriateness of the communicative approach in Vietnam: An interview study in intercultural communication (Master's thesis). La Trobe University, Victoria, Australia. ERIC E-Journal. Document No. ED 378839. Accessed on February 12, 2015.

5. Freemen, Diane, L. (2000), Techniques and Principles in Language Teaching. Oxford University Press.

6. Holliday, A. (1994). The house of TESEP and the communicative approach: the special needs of state English language education. ELT Journal, 48(1):3-11.

7. Hamid, M. O. \& Baldauf, R. B. (2008). Will CLT bail out the bogged down ELT in Bangladesh; English Today, Vol. 24, No. 3. Cambridge University Press.

8. Hymes, D. (1972). On Communicative Competence. In J.B. Pride \& J. Holmes (Eds.), Sociolinguistics. Harmondsworth: Penguin.

9. Islam, J. \& Bari, S. (2012). Implementation of CLT in Bangladesh and Thailand:Problems and Challenges, Outlooks: VUB, Vol. 2, Issue 1:32-42.

10. Karavas, Doukas, E. (1996). Using attitude scales to investigate teachers' attitudes to the communicative approach. ELT Journal, 50(3):187-196.

11. Liao, X. (2000). How communicative language teaching became acceptable in secondary schools in China. The Internet TESL Journal, 6(10). Retrieved from www.aitech.ac.jp/ iteslj/Articles/Liao-CLTinChina.html on January 21, 2016.

12. Pennycook, A. (1989). The concept of method, interested knowledge, and the politics of language teaching. TESOL Quarterly, 23(4):589-618.

13. Richards, J. C., \& Rodgers, T. S. (2003). Approaches and Methods in Language Teaching. Cambridge: Cambridge University 
Press.

14. Ramanathan, V. (1999). "English is here to stay: a critical look at institutional and educational practices in India", in TESOL Quarterly, 33, 2: 211-231.

15. Vassilopoulos, S. P. (2008) Coping strategies and anticipatory processing in high and low socially anxious individuals. Journal of Anxiety Disorders, 22(1):98-107.

16. Wilkins, D. A. (1972). "The linguistic and situational content of the common core in a unit credit system", in Systems Development in Adult Learning. Council of Europe, Strasbourg. 
